\title{
Surgical Outcomes in Cases of Marcus-Gunn Jaw-Winking Phenomenon
}

\section{Sthapit R P, ${ }^{1}$ Saiju R ${ }^{2}$}

${ }^{1}$ Department of Ophthalmology

Dhulikhel Hospital, Kathmandu University Hospiital

Dhulikhel, Kavre, Nepal.

${ }^{2}$ Tilganga Institute of Ophthalmology

Kathmandu, Nepal.

\section{Corresponding Author}

Purnima Rajkarnikar Sthapit

Department of Ophthalmology

Dhulikhel Hospital, Kathmandu University Hospiital

Dhulikhel, Kavre, Nepal.

E-mail: purnimark@gmail.com

\section{Citation}

Sthapit R P, Saiju R. Surgical Outcomes in Cases of Marcus-Gunn Jaw-winking Phenomenon Kathmandu Univ Med J 2015;49(1):34-7.

\section{ABSTRACT}

\section{Background}

Markus-Gunn Jaw-winking Phenomenon (MGJW) is a congenital ptosis associated with synkinetic movement of upper lid on masticating movements of jaw. It results from aberrant connection between motor division of trigeminal nerve and oculomotor nerve.

\section{Objective}

To investigate the clinical characteristics of MGJW phenomenon and evaluate its surgical outcomes of unilateral levator excision and frontalis suspension.

\section{Method}

It is a retrospective analysis of nine cases of MGJW phenomenon seen from 2007 to 2013 AD. The clinical features were recorded and analysed. Unilateral levator excision and frontalis suspension for the correction of synkinesis and ptosis was done for all the patients. The result of surgery was analysed.

\section{Result}

MGJW phenomenon was seen more in males. All the cases had unilateral ptosis with jaw winking phenomenon. Ipsilateral hypotropia and refractive errors were seen in $44 \%$. One week post operative margin reflex distance was good in $67 \%$ of cases. Persistent jaw-winking was seen in 3 cases, two underwent repeat surgery to abolish the synkinesis. At one year follow up, $33 \%$ had good margin reflex distance of more than $4 \mathrm{~mm}$ and $22 \%$ had fairly good margin reflex distance of $3 \mathrm{~mm}$.

\section{Conclusion}

Patients with Marcus Gunn jaw winking synkinesis can present at a wide age range. There may be an associated vertical muscle imbalance, which should be managed before ptosis surgery to avoid ptosis under correction. Unilateral frontalis flap suspension combined levator excision can correct ptosis very well for patients with Marcus-Gunn syndrome.

\section{KEY WORDS}

Congenital ptosis, frontalis sling, levator excision, markus gunn jaw winking synkinesis. 


\section{INTRODUCTION}

Blepharoptosis denotes droopiness of upper eyelid. Aetiology maybe myogenic, aponeurotic, neurogenic or mechanical. ${ }^{1}$ Among them, Marcus-Gunn Jaw-winking phenomenon (MGJW) is an unilateral (sometimes bilateral) congenital ptosis associated with synkinetic movement of upper lid resulting from aberrant connection between motor division of trigeminal nerve controlling masticating movements of jaw and oculomotor nerve innervating the levator palpebrae superiosus muscle. ${ }^{2}$ Hence upper eyelid motion is observed with stimulation of the ipsilateral pterygoid muscles for example while chewing is associated with different degrees of blepharoptosis which is known as synkinesis. ${ }^{3}$ The resting position of the involved eye maybe normal or ptotic, which elevates with opening mouth or movement of jaw to opposite side. Sometimes weakness of superior rectus muscle maybe associated with it. ${ }^{1}$ It occurs in approximately $5 \%$ of patients with "congenital ptosis" and sometimes associated with trauma, Duane syndrome and Waardenburg syndrome. ${ }^{4}$

Surgical treatment to correct both jaw-wink and ptosis involves complete disinsertion and thus disabling of levator aponeurosis followed by suspension of upper lid with silicon rod or autologus fascia lata to correct the ptosis. ${ }^{1}$ In this paper, we report our management technique and its outcome in a series of MGJW phenomenon.

\section{METHODS}

It was a retrospective analysis of nine cases with unilateral MGJW phenomenon that underwent surgical treatment from 2007 to 2013 AD. Patient age at presentation, sex, side of jaw wink, visual acuity, and any extraocular muscle imbalance were recorded. The degree of ptosis was measured by taking into account, the vertical palpebral aperture (PA) and margin reflex distance (MRD). Ptosis was recorded as mild ( $2 \mathrm{~mm}$ or less), moderate (3 $\mathrm{mm}$ ), or severe (4 $\mathrm{mm}$ or more) according to Beard classification.

Then all the patients underwent the same procedure of complete excision of levator aponeurosis after disinsertion and frontalis sling suspension using silicon rod. The patients were then assessed on post operative day seven, 30, and 90 and after one year. At each visit, PA and MRD were recorded to measure the treatment outcome. They were also assessed for remaining jaw wink and other complications when present.

\section{Surgical method}

All the surgery was performed with the patient under general anaesthesia. After painting and draping, the eyelid and forehead incisions for brow suspension were marked by using a Fox pentagon technique. Anaesthesia was supplemented by local infiltration of $5 \mathrm{ml}$ lignocaine $2 \%$ with 1:100,000 adrenaline and bupivicaine $0.5 \%$ (in equal quantities). BP blade no. 15 was used to make upper lid crease incision and three horizontal forehead incisions. The lid crease incision was further dissected to expose the upper border of tarsal plate and levator aponeurosis identified. It was then disinserted completely from its lower attachment thus forming a complete ptosis and dissected up to Whitnal ligament where it was excised completely. A silicon rod was then secured over the tarsal plate with 6-0 vicryl suture. Then a Wright's fascia needle was inserted from lower forehead incision to the skin crease incision, hooked the silicon rod to it and pulled back from the forehead incision. Similar procedure was done for the opposite end of the rod. Finally both ends of the silicon rod were brought out from the upper forehead incision thus forming a triangle. The silicon rod is then adjusted to bring the lid to the desired level and tied together with a sleeve and supplemented with $6 / 0$ vicryl suture for reinforcement. The ends were then buried inside the skin. The skin incisions were closed with $6 / 0$ vicryl. The skin crease incision is closed with an extra bite of orbicularis to superior border of tarsus to prevent lash ptosis. The eye was closed for 48 hours using Frost sutures and eye padded with ciprofloxacin eye ointment.

\section{RESULTS}

Mean patient age was 11.12 years (range, 5 to 19 years). $78 \%$ of them were males. Right eye was involved in $44 \%$ of the cases whereas there were no bilateral cases. Ipsilateral hypotropia was seen in four cases (44\%) with median visual acuity of $6 / 36$ (range, $6 / 24$ to $6 / 60$ ), compared with $6 / 6$ in four out of five cases without hypotropia. The median Margin reflex distance (MRD) was $2 \mathrm{~mm}$ (range, -5 to $3 \mathrm{~mm}$ ) before undergoing surgery. One week post operatively, as shown in Fig. 1, $67 \%$ ( 6 cases) had good

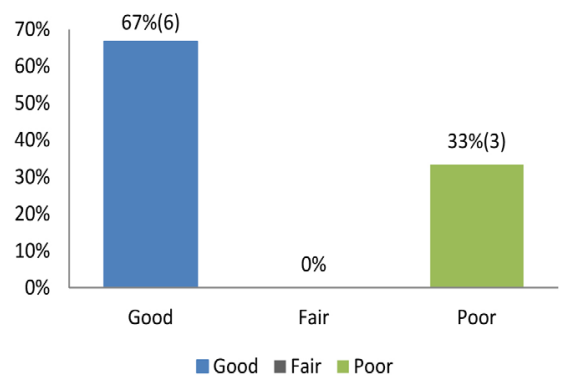

Figure 1. MRD at post operative day 7.

(MRD of 4-5mm) surgical outcome while 33\% (3 cases) had poor (MRD of $<$ or $=2 \mathrm{~mm}$ ) outcome. Post operative results at post operative day 30 and one year are shown in fig. 2 and 3 respectively. Persistent jaw-winking was seen in three cases, out of which, two underwent repeat surgery to abolish the synkinesis. Lagophthalmos and punctate keratitis were seen in five cases while two of them had lateral drooping. Rest of the patients had good lid contour. At one year follow up, 33\% had good MRD of more than $4 \mathrm{~mm}, 22 \%$ had fairly good and $44 \%$ had MRD of less than 
or equal to $2 \mathrm{~mm}$. Pre and post operative results of one of our cases is shown in fig. 4 and 5. Two of the patients had gone for repeat surgery for persistent synkinesis and one of them had entropion.

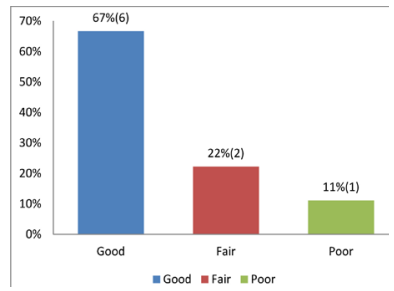

Figure 2. MRD at post operative day 30.

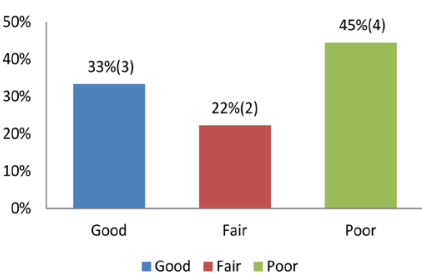

Figure 3. MRD at one year post operative.
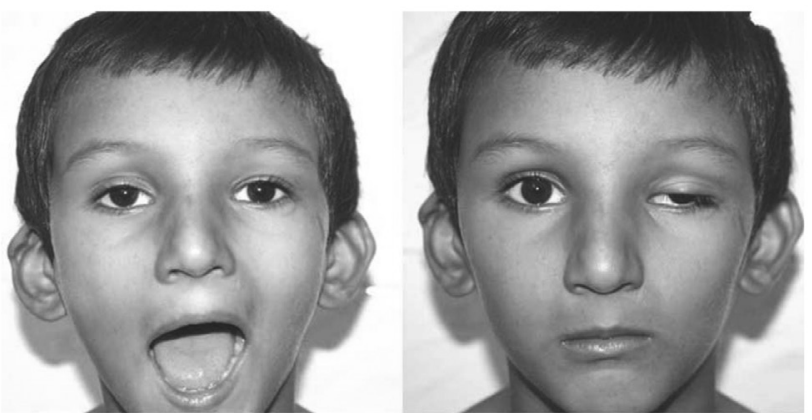

Figure 4. Pre-operative: Ptosis with MGJW. (Consent has been taken from the patient for publishing the photograph)

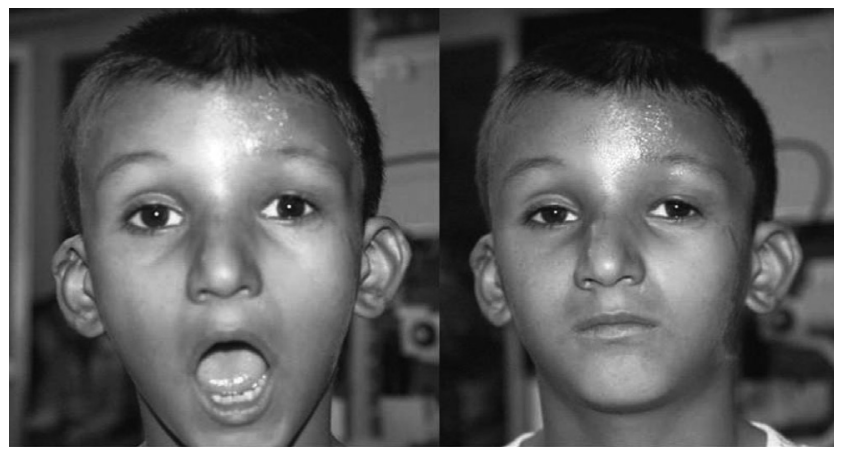

Figure 5. Post- operative: Ptosis and jaw wink abolished. (Consent has been taken from the patient for publishing the photograph)

\section{DISCUSSION}

Patients with MGJWS usually present in early childhood. Mean age of our patients was 11.12 years. Other studies also reported the similar age group of presentation; mean age of 5 years, ${ }^{5} 11.23$ yeas. ${ }^{6}$ In our study, $78 \%$ of patients were males although other studies did not have such a difference in frequency among male and females. ${ }^{5,7,8}$ Along with jaw winking, these patients also have various degree of ipsilateral ptosis and hypotropia. Many children learn to hold the jaw in a particular position to minimize the ptosis which Bower and Sullian describe it as patients 'habitual ptosis', which is often less than the patients true ptosis. ${ }^{7}$

Ipsilateral hypotropia was noted in four patients (44\%) with decreased visual acuity $(6 / 24$ to $6 / 60)$ in comparison to patients without hypotropia having normal visual acuity except in one patient. Other study by Bower and Sullivan also noted same in 8 patients (26\%), with the visual acuity ranging from $20 / 20$ to $20 / 40$, compared with $20 / 20$ in those without hypotropia. ${ }^{7}$

All the cases who presented to us had unilateral MJWS whereas few authors have reported bilateral cases as well. $7,9,10$

Regarding management of these patients, ptosis surgery by frontalis suspension aimed to restore position and, ideally, movement (although reduced) of the upper lids. For abolishing cosmetically significant jaw winking, excision of abnormally innervated levator muscle was also done. Post operatively, (33\%) three of our cases had persistent jaw winking; two of them underwent repeat surgery with complete resolution of jaw wink. In surgeries done by Khwarg et al also, in a total of 27 eyelids exhibiting jawwinking, 10 eyelids (37.0\%) showed complete resolution of jaw-winking, and 13 eyelids (48.2\%) showed mild winking postoperatively. ${ }^{9}$ Two out of 14 cases of Cates and Tyres had persistent jaw winking and they were of the opinion that standard levator resection was often unsatisfactory as the jaw-winking persisted so that the excision of the levator muscle should be placed well posterior to optimize the result. ${ }^{5}$

Unilateral brow ptosis often achieves asymmetry of movement of the upper lids since frontalis action may not be optimal. Hence many surgeons have reported of performing the same procedure on the normal side too claiming the improvement of frontalis action and symmetry. ${ }^{5,6,11}$ But in our cases we did unilateral levator excision and frontalis sling surgery and we had good surgical outcomes in $55 \%$ of cases with MRD of $3 \mathrm{~mm}$ or more at one year follow up. One of them is awaiting surgery. Mahajan et al also performed unilateral levator excision and frontalis suspension. According to them, combination of these two procedures gives fairly good results in treatment of Marcus Gunn jaw winking ptosis. ${ }^{12}$ Bowler and Sullivan, performed unilateral upper eyelid retractor surgery for patients with mild wink and a small degree of ptosis while for patients with a moderate or marked wink and ptosis, they performed bilateral levator weakening procedures and brow suspension with good surgical outcome in both groups. ${ }^{7}$ Similarly Zonghua in 2007 also performed unilateral levator excision and frontalis flap suspension with good correction in 26 (87\%) of 30 patients, fair results in $3(10 \%)$ patients. ${ }^{8}$ Therefore despite the potential advantages of bilateral surgery for unilateral ptosis like good lid symmetry in two eyes, the good surgical outcomes in the above studies including ours has shown that unilateral surgery limited to the ptotic lid is a good option. Often patients are also unwilling to get their normal eyes operated. 


\section{CONCLUSION}

Patients with Marcus Gunn jaw winking synkinesis can present at a wide age range. There may be an associated vertical muscle imbalance, which should be managed before ptosis surgery to avoid ptosis under correction.
Patients of MGJWS associated with ipsilateral hypotropia have marked diminution of vision while those without hypotropia usually have normal vision. Unilateral frontalis flap suspension combined with levator excision can correct ptosis fairly well for patients with Marcus-Gunn syndrome.

\section{REFERENCES}

1. Albert DM, Jakobiec FA. Principles and Practice of Ophthalmology. $2^{\text {nd }}$ ed. Philadelphia: WB Saunders; 2000.

2. Shah $A D$, Kumar $A B$, Kothari K. Bilateral Markus Gunn jaw winking synkinesis with monocular elevation deficiency: a case report and literature review. Ophthalmology 1999;106(6):1191-6.

3. AAO. Eyelids.Orbit, Eyelids and lacrimal systems. 2013-2014.

4. Kanski JJ, Bowling B. Clinical Ophthalmology: A Systematic Approach. $7^{\text {th }}$ ed. Philadelphia: Elsevier/Saunders; 2011.

5. Cates CA, Tyers AG. Results of levator excision followed by fascia lata brow suspension in patients with congenital and jaw-winking ptosis. Orbit 2008; 27(2):83-9.

6. Beard C. A new treatment for severe unilateral congenital ptosis and for ptosis with jaw winking. Am J Ophthalmol 1965; 59: 252-58.

7. Bowyer JD, Sullivan TJ. Management of Marcus Gunn jaw winking synkinesis. Ophthalmic plastic and reconstructive surgery 2004 Mar; 20(2):92-8.

8. Tian N, Zheng YX, Zhou SY, Liu JL, Huang DP, Zhao HY. Clinical characteristics of moderate and severe Marcus-Gunn jaw-winking synkinesis and its surgical treatment. Zhonghua Yan Ke Za Zhi 2007 Dec; 43(12):1069-72.

9. Khwarg SI, Tarbet KJ, Dortzbach RK,Lucarelli MJ. Management of moderate-to-severe Marcus-Gunn jaw-winking ptosis. Ophthalmology 1999 Jun; 106(6):1191-6.

10. Shah $A D$, Kumar $A B$, Kothari K. Bilateral Marcus Gunn jaw winking synkinesis with monocular elevation deficiency: a case report and literature review. Int Ophthalmol 2012 Apr;32(2):199-201.

11. Demirci H, Frueh BR, Nelson CC. Marcus Gunn jaw-winking synkinesis: clinical features and management. Ophthalmology 2010 Jul; 117(7):1447-52.

12. Mahajan M, Nicholson A, Ahuja A, Motwane S. Markus Gunn Jaw Winking Ptosis. Journal of the Bombay Ophthalmologists $2000 \mathrm{Jul}-$ Sept; 10(3):159-61. 